\title{
Comparison of High-Resolution Manometry in Patients Complaining of Dysphagia among Patients with or without Diabetes Mellitus
}

\author{
Koichi Muroi $^{\mathrm{a}}$ Ryoji Miyahara ${ }^{\mathrm{a}}$ Kohei Funasaka ${ }^{\mathrm{a}, \mathrm{b}}$ Kazuhiro Furukawa ${ }^{\mathrm{a}}$ Tsunaki Sawada $^{\mathrm{c}}$ \\ Keiko Maedac Takeshi Yamamurac Takuya Ishikawa ${ }^{a}$ Eizaburo Ohno ${ }^{a}$ Masanao Nakamura ${ }^{a}$ \\ Hiroki Kawashimac ${ }^{c}$ Takeshi Onoue $^{d}$ Hiroshi Arima $^{d}$ Yoshiki Hirooka $^{c}$ Mitsuhiro Fujishiro ${ }^{a}$ \\ aDepartment of Gastroenterology and Hepatology, Nagoya University Graduate School of Medicine, Nagoya, Japan; \\ ${ }^{b}$ Department of Gastroenterology, Fujita Health University School of Medicine, Toyoake, Japan; 'Department of \\ Endoscopy, Nagoya University Hospital, Nagoya, Japan; ' Department of Endocrinology and Diabetes, Nagoya \\ University Hospital, Nagoya, Japan
}

\section{Keywords}

Diabetes · Esophageal motility disorders · High-resolution manometry

\begin{abstract}
Introduction: Dysphagia is a common symptom that occurs in patients with diabetes mellitus (DM). There have been few prospective observational studies on esophageal motility disorders in DM using high-resolution manometry (HRM). This study aimed to clarify the characteristics of esophageal motility disorders using HRM in patients with dysphagia and compare them between DM and non-DM patients. Methods: Patients with dysphagia were prospectively recruited between October 2018 and July 2019. Patients $(n=89)$ underwent esophagogastroduodenoscopy and HRM and completed the Gastrointestinal Symptom Rating Scale (GSRS) questionnaire. Manometry parameters and motility disorder classifications were compared between DM and non-DM patients. We also investigated the differences in clinical backgrounds and questionnaire scores among DM patients with normal and abnormal manometry results. Results: A higher prevalence of esophageal motility disorder was observed in DM patients $(60 \%, 21 / 35)$ compared to non-DM patients $(29.6 \%, 16 / 54)(p=0.001)$. The prevalence of minor disorders
\end{abstract}

karger@karger.com www.karger.com/dig

Karger $\stackrel{\text { ' }}{5}$

马OPEN ACCESS
(C) 2020 The Author(s)

Published by S. Karger AG, Basel

This article is licensed under the Creative Commons AttributionNonCommercial-NoDerivatives 4.0 International License (CC BYNC-ND) (http://www.karger.com/Services/OpenAccessLicense) Usage and distribution for commercial purposes as well as any distribution of modified material requires written permission. such as ineffective esophageal motor disorder and fragmented peristalsis was significantly higher ( 45 vs. $11 \%)$, and the distal contractile integral, integrated relaxation pressure, and contractile front velocity values were lower in the DM group. Among DM patients, those with abnormal esophageal motility had a significantly higher prevalence of neuropathy, retinopathy, and nephropathy, as well as higher reflux or constipation scores on the GSRS, than those with normal results. Conclusions: Among patients with dysphagia, the frequency of minor esophageal motility disorders was higher in DM patients than in non-DM patients. Abnormal esophageal motility related to poor esophageal clearance was associated with higher prevalence of diabetic complications.

\section{Introduction}

Diabetes mellitus (DM) can cause various gastrointestinal symptoms [1]. The frequency of gastrointestinal symptoms in DM patients has been reported to be about $70 \%$, including heartburn (14\%) and dysphagia (8-27\%) [2]. These symptoms are thought to be due to esophageal motility disorders and gastroparesis. In 1967, Mandelstam et 
al. [3] reported esophageal motility disorders in DM patients and pointed out its relationship with gastroesophageal reflux disease (GERD). The causes of motility disorders are considered to be autonomic nerve disorders and transient hyperglycemia; therefore, esophageal motility disorders have been reported to worsen with longer duration of DM [4]. On the other hand, there have been reports that esophageal motility disorders occurred as from the earlier stages of DM, and the degree of the motility disorder was severe when neuropathy was observed [5-7]. Diabetic esophageal motility disorders are clinically important because they may be associated with delayed transit of meals and medicines, and gastrointestinal symptoms decrease the patient's quality of life $[8,9]$. However, it is not easy to endoscopically diagnose peristaltic disorders, and therefore many cases are not recognized or treated.

A few studies have evaluated esophageal motility in DM patients using conventional manometry. However, conventional manometry transmitted data through catheters containing pressure sensors at intervals of $5-7 \mathrm{~cm}$, so the diagnostic accuracy was low. In addition, the procedure was technologically complicated. Reported esophageal motility issues in DM patients include reduced peristaltic wave height or number, increased recurrent peristaltic waves, and reduced lower esophagus sphincter pressure. These manometry reports did not describe, in detail, the frequency and characteristics of the waveforms. High-resolution manometry (HRM) is now popularly used as a new esophageal pressure test, which measures pressure at intervals of $1 \mathrm{~cm}$ and can evaluate esophageal motility more accurately. In addition, it provides the calculation of specific waveform values and the systematic classification of esophageal motility disorders [10], which makes the diagnosis of esophageal disease easier.

According to previous reports, approximately $40 \%$ of patients complaining of dysphagia suffer from DM, and dysphagia symptoms and diabetic history were described as factors related to peristaltic disorders [11]. However, only few prospective observational studies have used HRM to evaluate esophageal motility disorders in DM patients. This study aimed to clarify the characteristics of esophageal motility disorders using HRM in patients with dysphagia and compare them between DM and non-DM patients.

\section{Materials and Methods}

\section{Subjects}

This was a single-center prospective study. Patients with dysphasia aged 20 years or older, and those who provided written informed consent were recruited between October 2018 and July 2019. Sub- jects underwent esophagogastroduodenoscopy (EGD) and HRM and completed the Gastrointestinal Symptom Rating Scale (GSRS) questionnaire. The exclusion criteria were neoplastic disease detected by EGD; a history of surgery, endoscopic therapy, chemotherapy, or radiation for aerodigestive tract diseases; and apparent organic diseases. Subjects were classified into the DM and non-DM groups. Diagnosis of DM was defined as a documented history of DM, or when there was no history, a hemoglobin Alc $\geq 6.5 \%$ and fasting plasma glucose $\geq 126 \mathrm{mg} / \mathrm{dL}$ in blood test results. Presumed DM diagnoses based on laboratory results were substantiated by an endocrinologist. This study was conducted after approval by the ethics committee of our institution and was performed in accordance with the Helsinki Declaration. This study was registered at the University Hospital Medical Information Network center (registration identification number: UMIN000032842).

\section{Study Assessments}

The HRM parameters and the classifications of motility disorders were compared between the DM and non-DM groups. We also investigated the differences in clinical backgrounds and GSRS scores among DM patients with normal and abnormal manometry results.

\section{Endoscopy}

Esophageal hiatal hernia, reflux esophagitis (modified Los Angeles [LA] classification: grade M, A, B, C, and D) [12], and gastric atrophy (Kimura-Takemoto classification: none, C-I, C-II, C-III, O-I, O-II, and O-III) [13] were evaluated. Each diagnosis was evaluated for all subjects by a board-certified fellow of the Japan Gastroenterological Endoscopy Society after endoscopy. Patients with LA grade A or higher were regarded as having erosive GERD. Those with a Kimura-Takemoto classification of C-II or higher were regarded as having atrophic gastritis $[14,15]$.

\section{Gastrointestinal Symptom Rating Scale}

Before the endoscopic examinations, we evaluated gastrointestinal dysfunction by administering the Japanese edition of the GSRS questionnaire. The GSRS questionnaire is composed of 15 items (abdominal pain, heart burn, acid regurgitation, sucking sensations in the epigastrium, nausea and vomiting, borborygmus, abdominal distention, pharyngeal discomfort, increased flatus, decreased passage of stools, increased passage of stools, loose stools, hard stools, urgent need for defecation, and feeling of incomplete evacuation), each rated according to the severity on a scale. The questionnaire is divided into subscales that allow separate evaluations of reflux, abdominal pain, indigestion, diarrhea, and constipation [16].

\section{HRM Protocol and Analysis}

HRM was performed to evaluate esophageal motility using the Starlet system (Starmedical Inc., Tokyo, Japan). The nasal passage was anesthetized with $2 \%$ lidocaine jelly. The manometric assembly was passed transnasally and positioned to record from the hypopharynx to the stomach. After the catheters were positioned, esophageal motility was evaluated by 10 sequential $5-\mathrm{mL}$ waterswallowing tests. The manometric data were analyzed manually using the Starlet software program according to the Chicago Classification ver.3.0 [10]. For each swallow, distal contractile integral (DCI), integrated residual pressure (IRP), contractile front velocity $(\mathrm{CFV})$, peristaltic breaks $(\mathrm{PB})$, and distal latency $(\mathrm{DL})$ were re- 
Table 1. Demographic and clinical characteristics of subjects

\begin{tabular}{|c|c|c|c|}
\hline & $\mathrm{DM}(n=35)$ & Non-DM $(n=54)$ & $p$ value \\
\hline Age, years (range) & $68(44-81)$ & $62(20-82)$ & 0.10 \\
\hline Sex, male, $n(\%)$ & $19(54)$ & $22(41)$ & 0.21 \\
\hline Smoker, $n(\%)$ & $17(49)$ & $17(31)$ & 0.10 \\
\hline \multicolumn{4}{|l|}{ Medications at hospital discharge, $n(\%)$} \\
\hline $\mathrm{H}_{2}$ receptor antagonist & $0(0)$ & $3(6)$ & 0.16 \\
\hline Prokinetic agent & $6(17)$ & $5(9)$ & 0.27 \\
\hline Calcium channel blocker & $6(17)$ & $7(13)$ & 0.59 \\
\hline Nitrate & $0(0)$ & $3(6)$ & 0.16 \\
\hline Laxative agents & $6(17)$ & $7(13)$ & 0.59 \\
\hline Antipsychotics & $2(6)$ & $5(9)$ & $0 . .11$ \\
\hline Hiatal hernia, $n(\%)$ & $27(77)$ & $30(56)$ & 0.04 \\
\hline Atrophic gastritis, $n(\%)$ & $14(40)$ & $12(22)$ & 0.07 \\
\hline Closed type & $3(9)$ & $5(9)$ & \\
\hline Opened type & $9(26)$ & $7(13)$ & \\
\hline
\end{tabular}

DM, diabetes mellitus; GERD, gastroesophageal reflux disease.

Fig. 1. Patient recruitment flowchart.

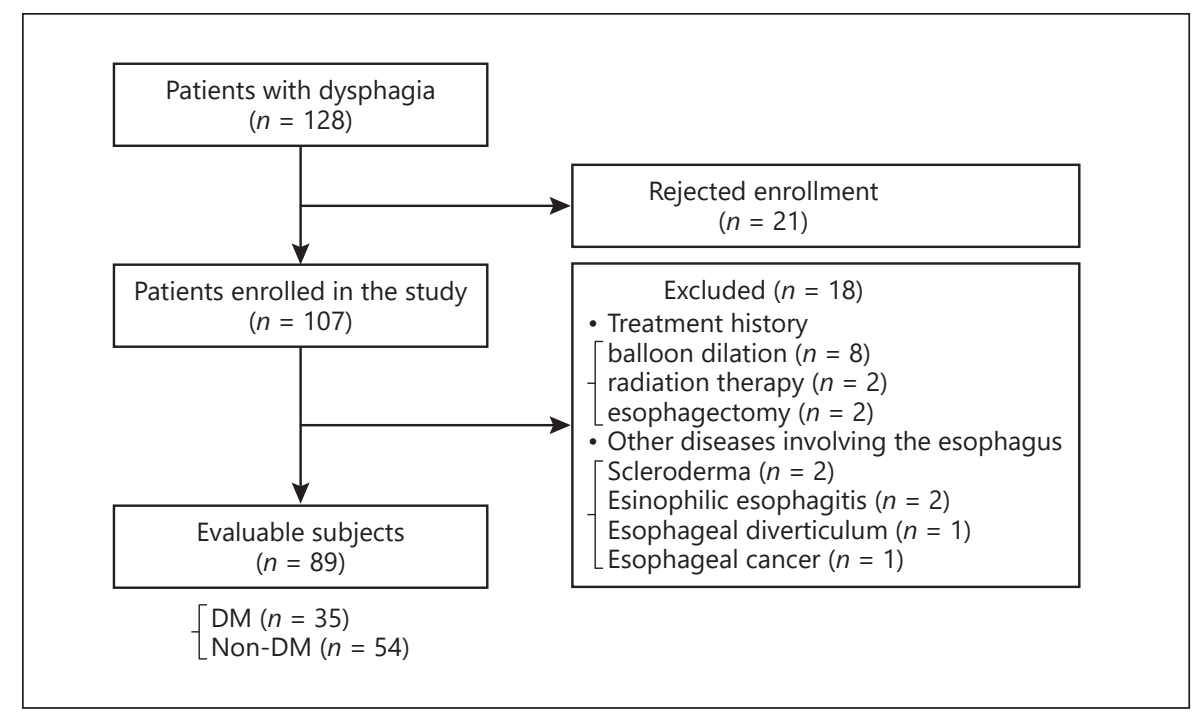

corded. Achalasia was diagnosed when there was no peristalsis, panesophageal pressurization, or premature contraction, and the value of IRP was $\geq 26 \mathrm{~mm} \mathrm{Hg}[17,18]$. Other esophageal manometry diagnoses were also evaluated, with the following cut-off values: Contractile vigor was assessed using the DCI (a contraction with a DCI $<500 \mathrm{~mm} \mathrm{Hg}$-s-cm was failed, a DCI $>500$ but $<1,000$ $\mathrm{mm} \mathrm{Hg}-\mathrm{s}-\mathrm{cm}$ was weak, and a hypercontractile swallow was defined as a DCI $\geq 10,000 \mathrm{~mm} \mathrm{Hg-s-cm).} \mathrm{A} \mathrm{premature} \mathrm{contraction}$ was defined as the presence of a DL $<4.5 \mathrm{~s}$ [19].

\section{Diabetes Complications}

Screening for diabetic neuropathy was performed using the Japanese version of the Italian Society of Diabetology questionnaire $[20,21]$. If the total score was $\geq 4$ points, the ankle reflex and vibratory sensation tests were performed to confirm neuropathy [22]. Diabetic retinopathy was estimated by dilated-pupil fundus examination by an ophthalmologist. Patients were diagnosed with retinopathy when a significant number of vascular abnormalities had formed in each fundus. Diabetic nephropathy was assessed by 
Table 2. Mean GSRS score of DM and Non-DM patients

\begin{tabular}{llll}
\hline & $\begin{array}{l}\text { DM } \\
(n=35)\end{array}$ & $\begin{array}{l}\text { Non-DM } \\
(n=54)\end{array}$ & $\begin{array}{l}p \\
\text { value }\end{array}$ \\
\hline Abdominal pain & $2.4 \pm 1.7$ & $1.9 \pm 1.3$ & 0.04 \\
Heart burn & $2.6 \pm 1.8$ & $2.3 \pm 1.4$ & 0.42 \\
Acid regurgitation & $2.3 \pm 1.8$ & $2.6 \pm 1.6$ & 0.91 \\
Sucking sensations in the & $2.1 \pm 1.5$ & $2.0 \pm 1.3$ & 0.62 \\
epigastrium & & & \\
Nausea and vomiting & $2.6 \pm 2.2$ & $2.2 \pm 1.5$ & 0.20 \\
Borborygmus & $1.8 \pm 1.2$ & $1.7 \pm 1.1$ & 0.72 \\
Abdominal distention & $2.3 \pm 2.1$ & $1.8 \pm 1.2$ & 0.28 \\
Pharyngeal discomfort & $1.9 \pm 1.3$ & $2.2 \pm 1.7$ & 0.64 \\
Increased flatus & $2.7 \pm 1.8$ & $2.0 \pm 1.3$ & 0.06 \\
Decreased passage of stools & $3.1 \pm 1.7$ & $2.1 \pm 1.6$ & 0.004 \\
Increased passage of stools & $2.1 \pm 1.8$ & $1.8 \pm 1.3$ & 0.54 \\
Loose stools & $2.3 \pm 1.7$ & $1.5 \pm 0.7$ & 0.06 \\
Hard stools & $2.6 \pm 1.7$ & $1.9 \pm 1.3$ & 0.02 \\
Urgent need for defecation & $2.6 \pm 2.0$ & $1.8 \pm 1.5$ & 0.04 \\
Feeling of incomplete evacuation & $2.9 \pm 1.8$ & $1.9 \pm 1.1$ & 0.005 \\
\hline
\end{tabular}

GSRS, Gastrointestinal Symptom Rating Scale; DM, diabetes mellitus.

a nephrologist's assessment of urinalysis and staged by urine albumin level and glomerular filtration rate.

\section{Statistical Analysis}

The prevalence of each factor was tested by the $\chi^{2}$ test or Fisher's exact test as appropriate. Age, body mass index (BMI), disease duration, blood test results, HRM parameters, and GSRS subscale scores were assessed by the Mann-Whitney $U$ test. Statistical analyses were performed using SPSS Statistics 24.0 (IBM Japan Ltd, Tokyo, Japan). The significance level was set at a 2 -tailed $p$ value $<0.05$.

\section{Results}

\section{Demographic and Clinical Characteristics of Subjects}

A total of 128 patients with gastrointestinal symptoms including dysphagia were screened, and 107 were enrolled during the study period. After excluding patients according to the exclusion criteria (neoplastic disease on endoscopic examination $[n=1]$; history of surgery, endoscopic therapy, chemotherapy, or radiotherapy for aerodigestive diseases $[n=12]$; other organic diseases such as scleroderma, eosinophilic esophagitis, and esophageal diverticulum $[n=5]), 89$ patients were considered as evaluable subjects (Fig. 1). Among the 89 patients (48 females and 41 males, median age of 66 years, median BMI of $22.75 \mathrm{~kg} / \mathrm{m}^{2}$ ), 35 patients were diagnosed as type $2 \mathrm{DM}$. The baseline characteristics of the DM and non-DM pa-
Table 3. Comparison of HRM diagnoses in DM and non-DM patients

\begin{tabular}{llll}
\hline Esophageal manometry diagnosis & $\begin{array}{l}\mathrm{DM} \\
(n=35)\end{array}$ & $\begin{array}{l}\text { Non-DM } \\
(n=54)\end{array}$ & $\begin{array}{l}p \\
\text { value }\end{array}$ \\
\hline $\begin{array}{l}\text { Disorders with EGJ outflow obstruction } \\
\quad \text { Achalasia }\end{array}$ & 0 & 5 & 0.06 \\
$\quad$ & & & \\
$\begin{array}{l}\text { Major disorders } \\
\quad \text { Distal esophageal spasm }\end{array}$ & 0 & 2 & 0.25 \\
$\quad$ Jackhammer esophagus & 1 & 4 & 0.36 \\
$\quad$ Absent contractility & 1 & 4 & 0.36 \\
$\begin{array}{l}\text { Minor disorders } \\
\quad \text { Ineffective esophageal motor disorder }\end{array}$ & 15 & 6 & 0.001 \\
$\quad$ Fragmented peristalsis & 4 & 0 & 0.01 \\
$\quad$ Normal & 14 & 33 & 0.09 \\
\hline
\end{tabular}

HRM, high-resolution manometry; DM, diabetes mellitus; EGJ, esophagogastric junction.

tients are provided in Table 1 . There were no differences in age, sex distribution, BMI, or smoking history between the groups. The results of GSRS scores between the groups are shown in Table 2 . Significantly higher scores were observed in the DM group in the items of abdominal pain, decreased passage of stools, hard stools, urgent need for defecation, and feeling of incomplete evacuation.

\section{Esophageal Motility Abnormalities}

The prevalence of esophageal motility abnormalities is shown in Table 3. The frequency of minor esophageal motility disorders, such as ineffective esophageal motor disorder (IEM) and fragmented peristalsis, was significantly higher in the DM group than in the non-DM group ( 43 vs. $11 \%, p=0.001 ; 11$ vs. $0 \%, p=0.01$, respectively). On the other hand, more patients in the non-DM group were diagnosed with disorders of esophagogastric junction outflow obstruction (achalasia) or major esophageal motility disorders (Jackhammer esophagus, absent contractility, and distal esophageal spasm) compared to those in the DM group, although there were no significant differences in the frequency of each classification. The comparison of HRM parameters between the DM and nonDM groups is shown in Table 4. In the DM group, the DCI, IRP, and CFV values were significantly lower $(p=$ $0.02, p=0.007$, and $p=0.01$, respectively).

\section{Relationship between Esophageal Motility}

Abnormalities and Diabetes Complications

When DM patients were categorized into normal and abnormal esophageal motility groups, there were 
Table 4. Comparison of HRM parameters in DM and non-DM patients

\begin{tabular}{lccc}
\hline Measure & $\mathrm{DM}(n=35)$ & Non-DM $(n=54)$ & $p$ value \\
\hline DCI, mm Hg-cm-s & $1,544.6(0.4-10,176.1)$ & $2,188.9(0-6,888.5)$ & 0.02 \\
IRP 4 s, mm Hg & $11.7(0-23.5)$ & $16.3(0-38.2)$ & 0.007 \\
CFV, cm/s & $3.8(2.2-25.8)$ & $4.9(1.8-44)$ & 0.01 \\
PB, cm & $3.0(0-17)$ & $1.4(0-15.4)$ & 0.18 \\
DL, s & $6.5(4-7.4)$ & $6.5(3.1-7.5)$ & 0.78 \\
\hline
\end{tabular}

Data are given as medians and ranges. HRM, high-resolution manometry; DM, diabetes mellitus; DCI, distal contractile integral; IRP, integrated residual pressure; CFV, contractile front velocity; $\mathrm{PB}$, peristaltic breaks; $\mathrm{DL}$, distal latency.

Table 5. Comparison of demographic and clinical characteristics in diabetic patients with abnormal versus normal manometry

\begin{tabular}{lcrc}
\hline & Abnormal $(n=21)$ & Normal $(n=14)$ & $p$ value \\
\hline Period of diabetes, years (range) & $26(2-42)$ & $7(0.5-39)$ & 0.06 \\
Hemoglobin Alc, \% (range) & $7.7(6.5-15.5)$ & $7.2(6.5-9.3)$ & 0.31 \\
Fasting plasma glucose, mg/dL (range) & $149(105-320)$ & $148(86-230)$ & 0.35 \\
Glucose-lowering therapies, $n$ (\%) & & \\
$\quad$ Oral hypoglycemic agent & $13(62)$ & $12(86)$ & 0.08 \\
$\quad$ Insulin & $11(52)$ & $5(36)$ & 0.56 \\
$\quad 6 L P-1$ receptor agonist & $6(29)$ & $2(14)$ & 0.73 \\
Diabetic complications, $n(\%)$ & $19(90)$ & $4(29)$ & $<0.001$ \\
$\quad$ Neuropathy & $12(57)$ & $1(7)$ & 0.001 \\
$\quad$ Retinopathy & $13(62)$ & $1(7)$ & 0.001 \\
$\quad$ Nephropathy & $17(81)$ & $9(64)$ & 0.64 \\
Items related to acid reflux & $6(29)$ & $3(21)$ & 0.50 \\
$\quad$ Hiatal hernia, $n$ (\%) & $5(24)$ & $9(64)$ & 0.03 \\
GERD, $n$ (\%) & $9(43)$ & $11(79)$ & 0.09 \\
$\quad$ Atrophic gastritis, $n(\%)$ & & & \\
$\quad$ Proton pump inhibitor/potassium competitive acid blocker & & \\
\hline
\end{tabular}

GLP, glucagon-like peptide; GERD, gastroesophageal reflux disease.

significant differences between both groups regarding the prevalence of diabetic complications (Table 5). Diabetic neuropathy ( 90 vs. $29 \%$; $p<0.001$ ), diabetic retinopathy ( 57 vs. $7 \% ; p=0.001$ ), and diabetic nephropathy (62 vs. $7 \% ; p=0.001)$ were more common in patients with abnormal esophageal motility. There were no significant statistical differences in hemoglobin A1c, fasting plasma glucose, glucose-lowering therapies, or the presence of hernia or reflux esophagitis between both groups. The percentages of atrophic gastritis (64 vs. $24 \% ; p=0.03)$ and the use of acid secretion inhibitors ( 79 vs. $43 \% ; p=0.09$ ) were higher in the normal group than in the abnormal group.

\section{Relationship between Esophageal Motility} Abnormalities and GSRS Subscales

In the DM and non-DM groups, the median scores for each of the GSRS subscales were evaluated. Patients in the DM group had significantly higher constipation symptom scores (2.8 vs. $1.6 ; p=0.01)$ than those in the non-DM group, but there were no significant differences in other scores (reflux, abdominal pain, indigestion, and diarrhea syndrome, and total score). The comparison of each of the GSRS subscales between the normal and abnormal esophageal manometry subgroups in the DM group is shown in Figure 2. Patients with abnormal manometry had higher scores for all subscales than those with normal manometry. The scores of reflux ( 2.0 vs. $1.0 ; p=0.02)$, constipation 

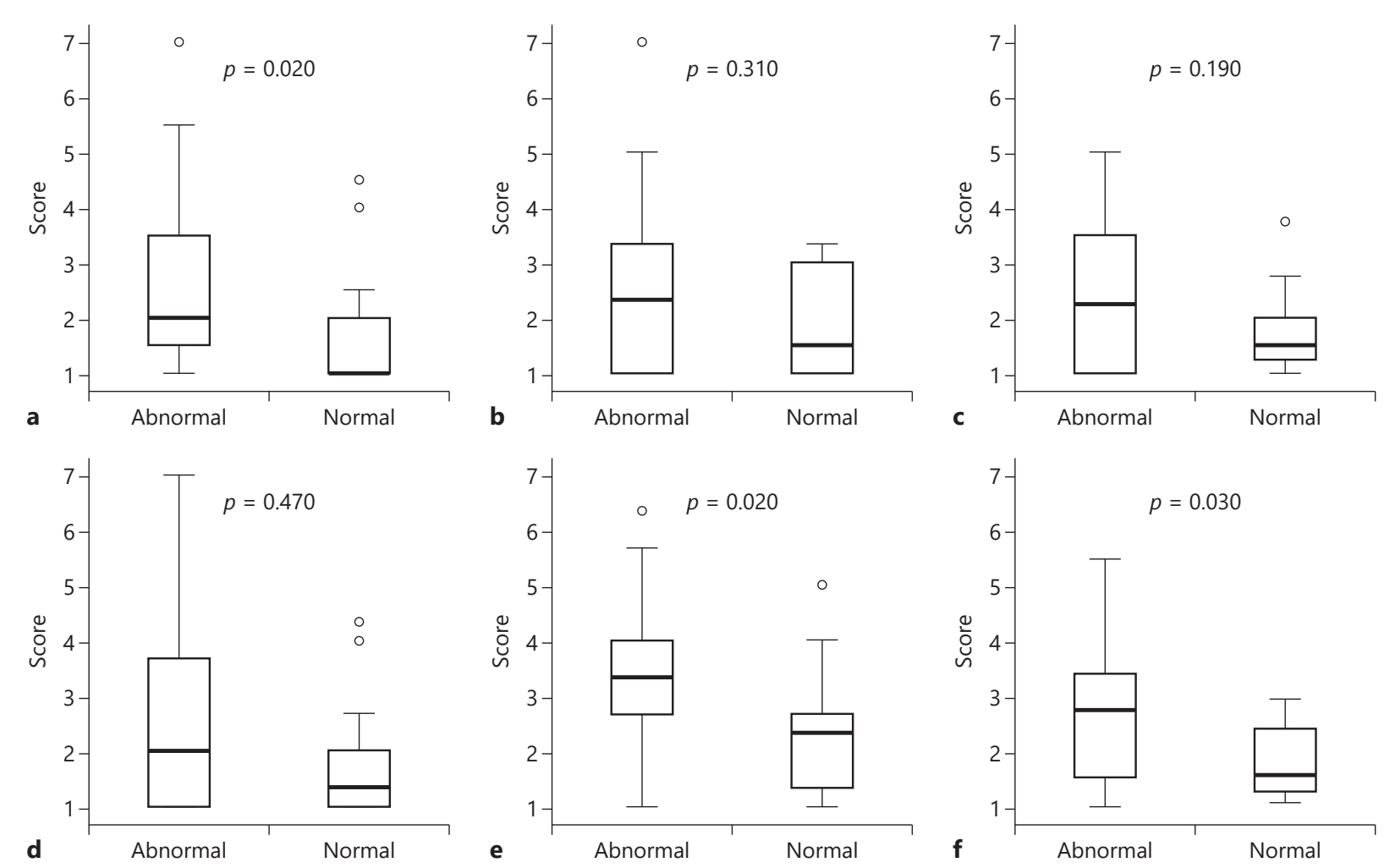

Fig. 2. Comparison of Gastrointestinal Symptom Rating Scale subscales in diabetic patients with abnormal versus normal manometry. a Reflux syndrome. b Abdominal pain syndrome. c Indigestion syndrome. d Diarrhea syndrome. e Constipation symptom. f Total score.

( 3.3 vs. $2.3 ; p=0.02$ ), and total scores ( 2.7 vs. $1.6 ; p=0.03$ ) were significantly higher in patients with abnormal esophageal manometry. On the other hand, there were no significant differences in abdominal pain, indigestion, or diarrhea syndrome scores between the groups.

\section{Discussion/Conclusion}

This study provided 3 novel findings regarding esophageal motility disorders in DM patients with dysphagia.

First, this study showed the prevalence of esophageal motility disorders and the characteristics of the HRM in DM patients with dysphagia. In our study, $60 \%$ of DM patients with dysphagia had a definable esophageal motility disorder, according to the Chicago Classification ver. 3.0. Moreover, the prevalence of minor disorders (IEM and fragmented peristalsis) was high in DM patients. According to the Chicago Classification, achalasia and major disorders (distal esophageal spasm, Jackhammer esophagus, and absent contractility) are recognized as disorders of esophageal movement, and minor disorders (IEM and fragmented peristalsis) are considered to be related to esophageal clearance. Therefore, it was suggested that DM patients might have poor esophageal clearance. A retrospective study did not show any significant difference in minor disorders between DM and non-DM patients [23], but this prospective study showed significant differences.

Furthermore, HRM could evaluate each parameter of esophageal motility. In the DM group, the median DCI, $\mathrm{CFV}$, and IRP values were lower than those in the nonDM group. This suggests that esophageal body pressure and the peristaltic velocity were decreased in DM patients, and these abnormalities may interfere with esophageal transport. One of the reasons for the noted decrease in these parameters may be the increase in gastric pressure due to obesity.

Higher gastric pressures in DM patients were reported in previous studies [24, 25], and patients in the DM group tended to have higher BMI values than those in the non- 
DM group in this study. Acid reflux has also been reported to be a factor in esophageal motility disorders [26]. Esophageal hiatal hernia and obesity, reduced lower esophageal sphincter pressure due to transient hyperglycemia, and autonomic neuropathy are reported to affect the onset of acid reflux [27]. Our results showed that the number of patients who took acid secretion inhibitors and the prevalence of atrophic gastritis were lower in DM patients with abnormal manometry compared to those with normal manometry. The rates of patients' use of acid secretion inhibitors for GERD treatment were $50 \%$ in the abnormal group and $67 \%$ in the normal group. This may indicate that the reduction in subjective GERD symptoms due to neuropathy is delaying therapeutic intervention [26].

Previous studies using conventional esophageal manometry have shown that esophageal peristaltic amplitude and velocity decrease in DM patients $[6,28,29]$. A few reports have quantitatively compared pressure and peristaltic velocity, and the incidence of motility disorders is unknown. In this study, it was possible to compare and accurately quantify HRM characteristics between $\mathrm{DM}$ and non-DM patients.

Second, we found that the presence of diabetic complications was associated with esophageal motility disorders. In this study, neuropathy was present in $66 \%$ of diabetic patients, and retinopathy or nephropathy was present in about $40 \%$. Patients with abnormal esophageal motility had significantly higher frequencies of these 3 major complications. Further, $43 \%$ of DM patients with abnormal esophageal motility had motility disorders classified as IEM. GERD occurred concurrently in about $50 \%$ of patients diagnosed as IEM, and neuropathy occurred in about $90 \%$ of them. Diabetic neuropathy, and especially diabetic autonomic disorder, has been considered to be the main cause of diabetic digestive tract dysfunction. There have been several previous reports on the association between GERD and autonomic dysfunction such as IEM [30, 31]. One report noted that a group of GERD patients with IEM had significantly reduced parasympathetic function compared to healthy people and that autonomic dysfunction was associated with GERD and IEM [32]. Therefore, we consider that the evaluation of diabetic neuropathy and GERD are necessary in patients with suspected esophageal motility disorders.

Third, diabetic patients with esophageal motility disorders had higher GSRS scores for reflux and constipation. This finding supports previous studies in which a questionnaire on gastrointestinal function showed the association between reflux or constipation symptoms and esophageal motility. Diabetic digestive tract dysfunction causes various digestive tract symptoms, with a high frequency of reported constipation, dysphagia, and heartburn $[2,8]$.

Acute and chronic hyperglycemia may have different effects on esophageal motility. In this study, the period of diabetes tended to be longer in DM patients (26 years) with abnormal manometry, compared to that of DM patients (7 years) with normal manometry. Moreover, DM patients with abnormal manometry had a higher incidence of diabetic complications compared to those with normal manometry, suggesting the long and chronic exposure to hyperglycemia. Thus, the development of IEM and fragmented peristalsis may be related to chronic hyperglycemia. On the other hand, acute hyperglycemia has been reported to reduce lower esophageal sphincter pressure and impair esophageal motility [27,33]. A relationship between the suppression of vagal cholinergic activity and the enhancement of visceral perception in the esophagus has also been suggested $[34,35]$. The total GSRS and reflux scores were higher among DM patients with abnormal manometry, compared to those with normal manometry. However, it was difficult to assess the effect of acute hyperglycemia in this study since there were no differences in fasting plasma glucose and glucose-lowering therapies in DM patients with or without abnormal manometry findings. Furthermore, gastrointestinal disorders caused by acute hyperglycemia may be reversible; therefore, successive monitoring is required to investigate the relationship between glycemic changes and gastrointestinal symptoms more closely.

In the past, esophageal motility disorder has been mainly assessed by physicians subjectively based on patients' complaints. Nowadays, HRM can provide physicians with an objective evaluation of a patient's symptoms, such as dysphagia. However, appropriate interventions for diagnosed motility disorders have not yet been determined. Based on the results of this study, HRM will enable clinicians to evaluate whether therapeutic agents that promote esophageal motility improve symptoms and whether esophageal motility disorders can be improved by appropriate glycemic control.

There are several limitations to this study. First, this study was conducted in a single hospital with a relatively small cohort. However, we were able to achieve statistically significant results despite the small number. Second, only the Unisensor catheter (Starlet) was used in this study. Unisensor and Manoscan ${ }^{\mathrm{TM}}$ (Medtronic, Minneapolis, MN, USA) catheters are available in the HRM system, and each catheter has different cutoff values for the Chicago classifications $[17,19]$. In our study, however, a comparison of the parameters for both catheter types re- 
sulted in no difference in esophageal manometry diagnoses. Third, the present study did not include asymptomatic patients due to insurance and ethical issues. Previous reports indicated that patients with DM might develop neuropathy in the absence of any symptoms [36, 37]; therefore, even asymptomatic DM patients may have silent esophageal motility disorders. This study focused on symptomatic patients because there have been few reports using HRM for DM patients. Based on our results, we would like to investigate esophageal motility disorders in DM patients further. Finally, multiple rapid swallows, previously reported for evaluating the significance of minor disorders [38, 39], were not performed in this study. If multiple rapid swallows were performed, the frequency of minor disorders might have changed.

In conclusion, among patients with dysphagia, the frequency of minor esophageal motility disorders characterized by reduced values of DCI, IRP, and CFV was higher in DM patients than in non-DM patients. Abnormal esophageal motility related to poor esophageal clearance was associated with higher prevalence of diabetic complications.

\section{Acknowledgements}

The authors thank the medical staff of the Department of Endocrinology and Diabetes for their cooperation in recruiting the target patients. We thank Dr. Kakushima Naomi for editing a draft of this manuscript.

\section{Statement of Ethics}

This study was conducted after approval by the ethics committee of the Nagoya University Hospital and performed in accordance with the Helsinki Declaration. Written informed consent was obtained from all subjects. This study was registered at the University Hospital Medical Information Network center (registration identification number: UMIN000032842).

\section{Conflict of Interest Statement}

The authors have no conflicts of interest to declare.

\section{Funding Sources}

The authors did not receive any funding.

\section{Author Contributions}

K.M. drafted and wrote the manuscript. R.M., K.F., T.S., K.M., T.Y., T.I., E.O., M.N., H.K., T.O., H.A., and Y.H. were involved in the acquisition of the data. K.M. analyzed the data. R.M., K.F., and M.F. revised the manuscript. M.F. gave the final approval of the manuscript.

\section{References}

1 Monreal-Robles R, Remes-Troche JM. Diabetes and the esophagus. Curr Treat Options Gastroenterol. 2017 Dec;15(4):475-89.

2 Feldman M, Schiller LR. Disorders of gastrointestinal motility associated with diabetes mellitus. Ann Intern Med. 1983 Mar;98(3):378-84.

3 Mandelstam P, Siegel CI, Lieber A, Siegel M. The swallowing disorder in patients with diabetic neuropathy-gastroenteropathy. Gastroenterology. 1969 Jan;56(1):1-12.

4 Annese V, Bassotti G, Caruso N, De Cosmo S, Gabbrielli A, Modoni S, et al. Gastrointestinal motor dysfunction, symptoms, and neuropathy in noninsulin-dependent (type 2) diabetes mellitus. J Clin Gastroenterol. 1999 Sep;29(2): 171-7.

5 He CL, Soffer EE, Ferris CD, Walsh RM, Szurszewski JH, Farrugia G. Loss of interstitial cells of cajal and inhibitory innervation in insulin-dependent diabetes. Gastroenterology. 2001 Aug;121(2):427-34.

6 Kinekawa F, Kubo F, Matsuda K, Kobayashi M, Furuta Y, Fujita Y, et al. Esophageal function worsens with long duration of diabetes. J Gastroenterol. 2008;43(5):338-44.
7 Wang X, Pitchumoni CS, Chandrarana K, Shah N. Increased prevalence of symptoms of gastroesophageal reflux diseases in type 2 diabetics with neuropathy. World J Gastroenterol. 2008 Feb 7;14(5):709-12.

8 Goyal RK, Spiro HM. Gastrointestinal manifestations of diabetes mellitus. Med Clin North Am. 1971 Jul;55(4):1031-44.

9 Kong MF, Horowitz M, Jones KL, Wishart JM, Harding PE. Natural history of diabetic gastroparesis. Diabetes Care. 1999 Mar;22(3):503-7.

10 Kahrilas PJ, Bredenoord AJ, Fox M, Gyawali CP, Roman S, Smout AJ, et al. The Chicago classification of esophageal motility disorders, v3.0. Neurogastroenterol Motil. 2015 Feb;27(2):160-74.

11 Boltin D, Zvidi I, Steinmetz A, Bernstine H, Groshar D, Nardi Y, et al. Vomiting and dysphagia predict delayed gastric emptying in diabetic and nondiabetic subjects. J Diabetes Res. 2014;2014:294032.

12 Lundell LR, Dent J, Bennett JR, Blum AL, Armstrong D, Galmiche JP, et al. Endoscopic assessment of oesophagitis: clinical and functional correlates and further validation of the
Los Angeles classification. Gut. 1999 Aug; 45(2):172-80.

13 Kimura K, Takemoto T. An endoscopic recognition of the atrophic border and its significance in chronic gastritis. Endoscopy. 1969; 1(3):87-97.

14 Kamada T, Haruma K, Inoue K, Shiotani A. [Helicobacter pylori infection and endoscopic gastritis: Kyoto classification of gastritis]. Nihon Shokakibyo Gakkai Zasshi. 2015 Jun; 112(6):982-93.

15 Sugimoto M, Ban H, Ichikawa H, Sahara S, Otsuka $\mathrm{T}$, Inatomi $\mathrm{O}$, et al. Efficacy of the Kyoto classification of gastritis in identifying patients at high risk for gastric cancer. Intern Med. 2017;56(6):579-86.

16 Kinoshita Y, Miki M, Tanimura T. [QOL of Japanese patients with GERD]. Nippon Rinsho. 2007 Aug;65(8):1539-44.

17 Kuribayashi S, Iwakiri K, Kawada A, Kawami N, Hoshino S, Takenouchi N, et al. Variant parameter values-as defined by the Chicago Criteria-produced by ManoScan and a new system with Unisensor catheter. Neurogastroenterol Motil. 2015 Feb;27(2):188-94. 
18 Kawami N, Hoshino S, Hoshikawa Y, Takenouchi N, Hanada Y, Tanabe T, et al. Validity of integrated relaxation pressure cutoff value used in Starlet (high-resolution manometry system). J Nippon Med Sch. 2020 Jan 10; 86(6):322-6.

19 Kuribayashi S, Iwakiri K, Shinozaki T, Hosaka H, Kawada A, Kawami N, et al. Clinical impact of different cut-off values in high-resolution manometry systems on diagnosing esophageal motility disorders. J Gastroenterol. 2019;54(12):1078-82.

20 Gentile S, Turco S, Corigliano G, Marmo R. Simplified diagnostic criteria for diabetic distal polyneuropathy. Preliminary data of a multicentre study in the Campania region. S.I.M.S.D.N. Group. Acta Diabetol. 1995 Mar; 32(1):7-12.

21 Kanji JN, Anglin RE, Hunt DL, Panju A. Does this patient with diabetes have large-fiber peripheral neuropathy? JAMA. 2010 Apr 21; 303(15):1526-32.

22 Haneda M, Noda M, Origasa $H$, Noto $H$, Yabe D, Fujita Y, et al. Japanese clinical practice guideline for diabetes 2016. Diabetol Int. 2018 Feb;9(1):1-45.

23 George NS, Rangan V, Geng Z, Khan F, Kichler A, Gabbard S, et al. Distribution of esophageal motor disorders in diabetic patients with dysphagia. J Clin Gastroenterol. 2017 Nov/Dec;51(10):890-5.

24 Pandolfino JE, El-Serag HB, Zhang Q, Shah N, Ghosh SK, Kahrilas PJ. Obesity: a challenge to esophagogastric junction integrity. Gastroenterology. 2006 Mar;130(3):639-49.
25 Roman S, Marjoux S, Thivolet C, Mion F. Oesophageal function assessed by high-resolution manometry in patients with diabetes and inadequate glycaemic control. Diabet Med. 2014 Nov;31(11):1452-9.

26 Kahrilas PJ, Dodds WJ, Hogan WJ, Kern M, Arndorfer RC, Reece A. Esophageal peristaltic dysfunction in peptic esophagitis. Gastroenterology. 1986 Oct;91(4):897-904.

27 De Boer SY, Masclee AA, Lam WF, Lamers CB. Effect of acute hyperglycemia on esophageal motility and lower esophageal sphincter pressure in humans. Gastroenterology. 1992 Sep;103(3):775-80.

28 Ippoliti A. Esophageal disorders in diabetes mellitus. Yale J Biol Med. 1983 Jul-Aug;56(4): 267-70.

29 Kinekawa F, Kubo F, Matsuda K, Fujita Y, Tomita T, Uchida Y, et al. Relationship between esophageal dysfunction and neuropathy in diabetic patients. Am J Gastroenterol. 2001 Jul;96(7):2026-32.

30 Deprez P, Fiasse R. Healing of severe esophagitis improves esophageal peristaltic dysfunction. Dig Dis Sci. 1999 Jan;44(1):125-33.

31 Sugiura T, Iwakiri K, Kotoyori M, Kobayashi M. Relationship between severity of reflux esophagitis according to the Los Angeles classification and esophageal motility. J Gastroenterol. 2001 Apr;36(4):226-30.

32 Manabe N, Haruma K, Hata J, Nakamura K, Tanaka S, Chayama K. Autonomic nerve dysfunction is closely associated with the abnormalities of esophageal motility in reflux esophagitis. Scand J Gastroenterol. 2003 Feb; 38(2):159-63.
33 Rayner CK, Samsom M, Jones KL, Horowitz M. Relationships of upper gastrointestinal motor and sensory function with glycemic control. Diabetes Care. 2001 Feb;24(2):37181.

34 Lam WF, Masclee AA, de Boer SY, Lamers CB. Hyperglycemia reduces gastric secretory and plasma pancreatic polypeptide responses to modified sham feeding in humans. Digestion. 1993;54(1):48-53.

35 Kamath MV, Tougas G, Fitzpatrick D, Fallen EL, Watteel R, Shine G, et al. Assessment of the visceral afferent and autonomic pathways in response to esophageal stimulation in control subjects and in patients with diabetes. Clin Invest Med. 1998 Jun;21(3):100-13.

36 Rathmann W, Enck P, Frieling T, Gries FA. Visceral afferent neuropathy in diabetic gastroparesis. Diabetes Care. 1991 Nov;14(11): 1086-9.

37 Frøkjaer JB, Andersen SD, Ejskaer N, FunchJensen P, Arendt-Nielsen L, Gregersen H, et al. Gut sensations in diabetic autonomic neuropathy. Pain. 2007 Oct;131(3):320-9.

38 Shaker A, Stoikes N, Drapekin J, Kushnir V, Brunt LM, Gyawali CP. Multiple rapid swallow responses during esophageal high-resolution manometry reflect esophageal body peristaltic reserve. Am J Gastroenterol. 2013 Nov 108(11):1706-12.

39 Penagini R, Gyawali CP. Evaluation of esophageal contraction reserve using HRM in symptomatic esophageal disease. J Clin Gastroenterol. 2019 May/Jun;53(5):322-30. 